\title{
Numerical Analysis of the Blast Wave Propagation due to Various Explosive Charges
}

\author{
Lucia Figuli $\left(\mathbb{D},{ }^{1}\right.$ Damjan Cekerevac $\mathbb{D}^{2},{ }^{2}$ Chiara Bedon $\left(\mathbb{D},{ }^{3}\right.$ and Bohuš Leitner $\mathbb{D}^{1}$ \\ ${ }^{1}$ Faculty of Security Engineering, University of Žilina, Univerzitná 8215/1, Žilina 01026, Slovakia \\ ${ }^{2}$ University of Coimbra, Institute for Sustainability and Innovation in Structural Engineering, Rua Luis Reis Santos-Polo II, \\ Coimbra 3030-788, Portugal \\ ${ }^{3}$ Department of Engineering and Architecture, University of Trieste, Piazzale Europa 1, Trieste 34127, Italy
}

Correspondence should be addressed to Lucia Figuli; lucia.figuli@fbi.uniza.sk

Received 3 July 2020; Revised 5 September 2020; Accepted 22 September 2020; Published 6 October 2020

Academic Editor: Luigi Di Sarno

Copyright (C) 2020 Lucia Figuli et al. This is an open access article distributed under the Creative Commons Attribution License, which permits unrestricted use, distribution, and reproduction in any medium, provided the original work is properly cited.

\begin{abstract}
Blast events and scenarios, as known, represent extreme phenomena that may result in catastrophic consequences, both for humans and structures. Accordingly, for engineering applications, the reliable description of expected blast waves is a crucial step of the overall design process. Compared to ideal theoretical formulations, however, real explosive events can be strongly sensitive to a multitude of parameters and first of all to the basic features (size, type, shape, etc.) of the charge. In this regard, several advanced computer codes can be used in support of design and research developments. Besides, the input parameters and solving assumptions of refined numerical methods are often available and calibrated in the literature for specific configurations only. In this paper, with the support of the ANSYS Autodyn program, special care is dedicated to the numerical analysis of the blast wave propagation in the air due to several charges. Five different explosives are taken into account in this study, including RDX, DAP-2, DAP-E, Polonit-V, and homemade ANFO. The effects of different mixtures are thus emphasized in terms of the predicted blast wave, as a function of a given control point, direction, explosive mass, and composition. As shown, relatively scattered peak pressure estimates are collected for a given explosive. Comparative results are hence proposed towards selected experimental data of the literature, as well as based on simple analytical predictions. The collected overpressure peak values are thus discussed for the selected explosive charges.
\end{abstract}

\section{Introduction}

The research efforts in the field of blast-protective design, especially for strategic buildings and infrastructures, are not new [1]. In fact, a number of studies have been performed, in the past decades, by several military and civil science teams and laboratories, with the support of field experiments and/ or numerical methods. Such a kind of design issue is in fact of interest for various types of engineering applications.

Several efforts are especially carried out on the side of the structural design and the (even complex) mechanical analysis of blast-resistant and protective structures that could properly withstand the input blast waves $[2,3]$.

In general, both "nonstructural" and "structural" mitigation measures can be detected in blast-related design aspects. In the first case, the "nonstructural" mitigation measures can be either passive or active. Their goal is to address the reduction of the probability of occurrence of a certain accidental scenario and thus minimize the intensity of a possible hazardous event that may occur. The category of "structural" mitigation measures, on the contrary, focuses on structural measures that need to be adopted in order to protect specified areas against explosions (and even fire). These areas include zones such as muster areas and temporary shelters. The major structural mitigation solutions are thus aimed at the satisfaction of two basic goals, namely, (i) the improvement of the ductile capacity of areas where severe effects due to blast waves are expected and (ii) use of blast-resisting walls and strengthening of secondary structures so that they could also carry on part of the blast load. In 
the second case, a multitude of different solutions can be found in the literature for blast walls, depending on their final destination and use.

An overview of blast mitigation measures for offshore structures was presented in [4]. It was shown that, for offshore structures, for example, blast walls are usually made of steel and provide a barrier that protects a muster area from the blast impact. They can be fabricated from profiled plates or from plates with stiffeners. Moreover, blast walls isolate nonhazardous areas and therefore minimize the effects of explosive loads. According to the literature, other materials such as stainless steel, aluminium, and fibrereinforced polymers have been successfully tested for various blast loadings in the form of plates or sandwich panels. "Soft targets," in this context, are particularly vulnerable to potential blast events and indicate places that may be selected by terrorists in their effort to maximize casualties, thus inflicting fear to the population and attaining media coverage $[5,6]$. These may include critical infrastructures, key resources, or key assets which are usually without proper protection and that are open to the public by their purpose.

Blast scenarios, however, are well known to represent unexpected events that may result in catastrophic consequences [7-11]. Serious damage could arise both to people as well as civilian and industrial objects and constructed facilities. Accordingly, the adequate blast design of structures is strictly related to appropriate knowledge on the input load and thus on a reliable description of blast waves and related effects. On the side of the structure, the final result typically takes the form of a complex mathematical problem that must account for high strain loading effects and dynamic nonlinearities. A number of literature studies can be found on the blast performance analysis of various constructional systems and materials, including metal sandwich panels [12-21], aluminium panels [22-25] and steel structures [26-29], reinforced concrete (RC) and RC-strengthened slabs and components [30-39], and glass assemblies and systems [40-43].

On the side of the input blast pressure, the calculation stage often requires major efforts but can take advantage of advanced numerical tools [44-48]. The intrinsic flexibility of computer codes can efficiently support the analysis of general explosive scenarios. However, their basic input assumptions could require dedicated calibrations, or they result in uncertain definitions for various explosive charges. In this regard, simplified analytical models can offer to designers an alternative tool for the description of the required blast waves [49-53]. However, in most of the cases, the real explosive event is only roughly captured, and field experiments still represent the most reliable approach for detailed investigations on the complex blast-related phenomena [54-56]. In this paper, a numerical study is presented for the blast wave propagation analysis. Based on field experiments inclusive of different explosive types, the numerical analysis is carried out with the ANSYS Autodyn software program [57]. The effects of five different explosive charges are thus investigated (RDX, DAP-2, DAP-E, Polonit-V, and homemade ANFO). The numerical predictions are thus assessed towards experimental and analytical estimates of the literature.

\section{Blast Wave Propagation}

2.1. Background. Let us assume the explosive charge in Figure 1 at a distance $H$ from the ground. The chemical explosion (i.e., due to explosive substances) theoretically starts from the point of detonation (i.e., $R=0$, the distance) at time instant $t=0$. The explosive charge is divided in time $t$ into two zones, namely, the zone of reacted and unreacted explosion. A thin zone of chemical reaction, called "blast wave front," divides the two zones. The reference parameters of a blast wave front are known to change suddenly, and the pressure of the moving explosive gases is also known to decrease continually, down to the atmospheric pressure.

Such a condition represents a limit for the explosive propagation. After this time instant, the blast wave is in fact not supported by the explosive gases anymore, and thus, it is spread separately. In the ideal case of a spherical explosive charge, the blast wave is theoretically propagated with a constant velocity $D$ and has the form of a hemisphere (when the explosion occurs on the ground) or the form of a sphere (in the case of an explosive event above the ground (in the air)). In the case of ground explosions, moreover, the weight of explosion is theoretically assumed as twice the nominal value, but the real ratio of the weight strongly depends on the characteristics of the contact environment. Finally, it is also known that, in the typical blast wave, the air particles are pressed and moved. When the blast wave impacts on a rigid barrier, the reflected overpressure is much greater than the overpressure of the blast wave before the impact.

2.2. Explosive or Gas Waves. The detonation generates hot gases which expand, forcing out the volume they occupy. As a consequence, a layer of compressed air called blast wave forms in front of this gas volume containing most of the energy released by the explosion (Figure 2).

The effect of the blast wave depends mainly on the sort of detonation and on the stand-off distance (i.e., between the blast source and the target). The blast wave rapidly increases to a value of pressure above the ambient atmospheric pressure (positive phase). After a short time, the pressure may drop below the ambient pressure. This phase is called a negative phase. During it, a partial vacuum is generated, and air is sucked in. This is also accompanied by high suction winds that carry the debris for a long distance away from the explosion source.

The positive phase has a shorter duration and a higher intensity than the negative phase. As the stand-off distance increases, moreover, the duration of the positive phase for the blast wave increases, thus resulting in lower amplitude and longer duration for the corresponding shock impulse. As far as the reflected wave must be described, the overpressure peak $P_{+}$ (in $\mathrm{MPa}$ ) represents one of the key parameters to predict, and it depends on several explosion parameters. Based on research efforts of last decades, various closed-form analytical solutions can be found in the literature [54-56]. Many other influencing parameters are then involved in the empirical description of an expected blast wave which is confined and can further interact with the ground or with impacted surfaces [52]. 


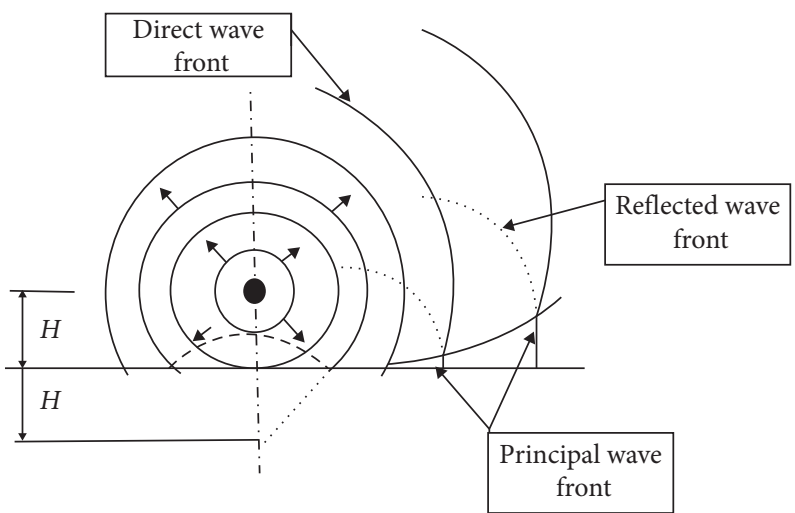

FIGURE 1: Schematic representation of the progressive position of wave fronts due to an explosive event [53].

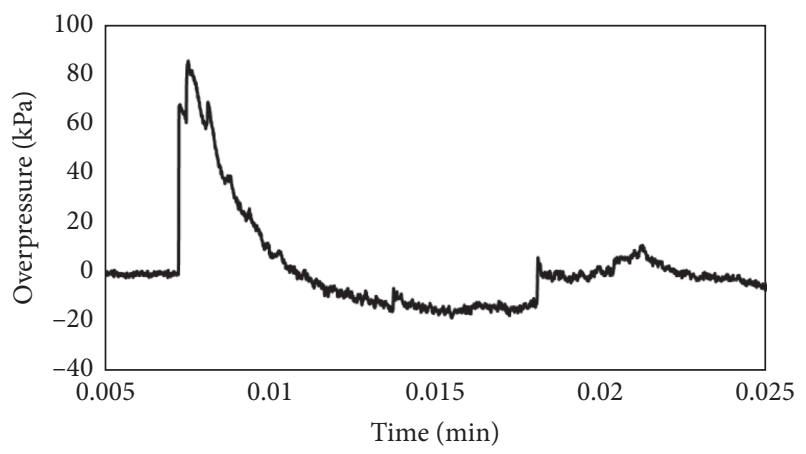

(a)

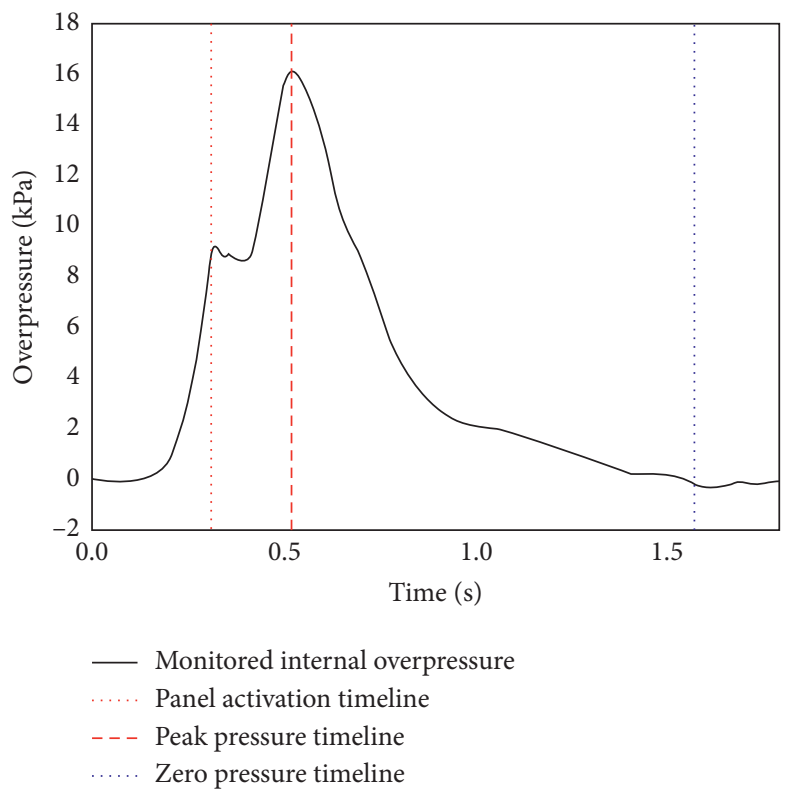

(b)

Figure 2: Examples of overpressure-time histories due to (a) an explosive or (b) a gas.

For a given ideal spherical blast charge, a common aspect of all the available empirical formulations is the definition of the well-known scaled distance $Z$ that is based on a reference TNT weight (or equivalent charge mass):

$$
Z=\frac{R}{W^{1 / 3}}
$$

where $R$ is the real distance of the target (structure) from the explosion (in $\mathrm{m}$ ) and $W$ is the charge weight (in $\mathrm{kg}$ ) for the explosive event in the air. For explosions on the surface, the charge mass is doubled.

In this paper, the overpressure peak $P_{+}$is calculated by adapting the original Sadovskij's proposal for $1 \leq Z \leq 15 \mathrm{~m}$ [53]:

$$
P_{+}=\frac{0.076}{Z}+\frac{0.255}{Z^{2}}+\frac{0.650}{Z^{3}}
$$

By using the improved formulation that was originally presented in [56],

$$
P_{+}=\left(\frac{0.202}{Z}+\frac{0.224}{Z^{2}}+\frac{1.182}{Z^{3}}\right) \cdot 0.5 \cdot e^{0.035 R} .
$$

In [56], the above expression was found to offer a rather close correlation between the analytical estimates from equation (3) and a selection of field experimental data (130 tests) from improvised explosive devices (IED). Equation (3) can be used in the distance $R$ when $1 \leq Z \leq 10 \mathrm{~m}$ or even for $Z>10 \mathrm{~m}$, with

$$
e^{0.035 R}=1 .
$$

The novel aspect of equation (3) is that the definition of the scaled distance $Z$ in equation (1) is based on a scaled weight $W_{\mathrm{R}}$ that accounts for several features of the explosive charge and replaces the original $W$ term. This is particularly 
advantageous and realistic for non-TNT charges and IED explosives in general, given that [56]

$$
W_{R}=W_{\text {exp }} \cdot k_{E} \cdot k_{G} \cdot k_{v}
$$

where $W_{\exp }$ (in $\mathrm{kg}$ ) is the actual explosive charge and $k_{\mathrm{G}}$ accounts for the blast wave geometry. Typical values are $k_{\mathrm{G}}=0.5$ or 1 for detonations in a free space or on the ground surface, respectively. Moreover, $k_{\mathrm{E}}$ is the factor of charge for leakiness, given by

$$
k_{E}=0.2+\frac{0.8}{1+k_{B}},
$$

where $k_{\mathrm{B}}$ represents the ballistic ratio (namely, the ratio of packaging weight and explosive weight). The major advantage of equation (5), and thus of the final estimate of equation (3), is given by the proposed $k_{\mathrm{v}}$ coefficient that can be calculated as a function of the explosive pressure $P_{\mathrm{Cj}}$ and its density $\rho[56]$ :

$$
k_{v}=0.085\left(\frac{P_{C j}}{\rho}\right) .
$$

\subsection{Numerical Analysis}

2.3.1. Objective. In this paper, the shock wave propagation through air is numerically modelled using ANSYS Autodyn [57]. More in detail, all the numerical models herein presented were created using the Autodyn 2D code. Accordingly, the $1 \mathrm{D}$ simulation was first performed in order to determine the pressures resulting from the detonation of different explosive types, at various distances. The problem was thus modelled using a 2D Eulerian multimaterial solver and wedge elements. The modelled part (with a length equal to $3 \mathrm{~m}$, in this study) was defined with a radial symmetry and filled with the explosive and air materials. Such a reference modelling approach is commonly used for similar purposes due to its simplicity and computational efficiency.

2.3.2. Reference Experiments. Figuli et al. reported in [54-56] an experimental investigation aimed at describing the blast wave propagation due to different charges, with a focus on the influence of geometry of charge features. The set of field tests took place at Military Technical and Testing Institute Zahorie (Ministry of Defence of the Slovak Republic). Various charge shapes (i.e., cylinder, sphere, and irregular shapes) and different types of explosives were in fact taken into account for the field tests (Figure 3 ).

For the numerical investigation reported in this paper, based on the selection of the past experimental outcomes, the attention was thus focused on five different explosives, characterized by mostly different features and thus expected wave propagation properties, as follows [54-56]:

(i) RDX: a white solid and one of the most powerful and devastating explosives

(ii) DAP-2: made from a mixture of ammonium nitrate, kerosene, and dye (iii) DAP-E: used for both over- and underground blasting operations due to its lack of danger of gas, vapour, and dust explosions

(iv) Polonit-V: given by a mixture of ammonium nitrate, kerosene, charcoal, ground TNT, and water-resistant additives

(v) ANFO (ammonium nitrate-fuel oil, with homemade mixture): a mixture of GPN HD Ammonitrate 33.5 (composed of $33.5 \%$ of ammonium nitrate- $16.7 \%$ of nitric nitrogen and $16.8 \%$ of ammoniacal nitrogen) and fuel oil Extra M2T (5\% of charge weight) was taken into account in this research investigation

The reference features for the selected charges are summarized in the description of numerical methods and assumptions.

In the numerical analysis, special care was also paid to the boundary conditions of the reference field experiments. For the whole experimental program, the explosive charge was in fact positioned on a wooden base (at a given height $H=1.6 \mathrm{~m}$ from the ground), so as to refer to the average height of the human chest (Figure 4). The maximum overpressure from each experiment was measured using blast pressure sensors (type 137A23 and 137A24 PCB Piezotronics). The experimental pressure histories, accordingly, were registered in various directions in order to support a more detailed description of the blast wave propagation in air (at a distance of $2 \mathrm{~m}$ from the detonation). To this aim, all the sensor tips in use were oriented towards the epicentre of the explosion (see Figure 4(a)). At the time of the experiments, additional sensors were also positioned at $5 \mathrm{~m}, 10 \mathrm{~m}$, and $20 \mathrm{~m}$ distances from the detonation point.

2.3.3. Solving Approach. The basics of shock physics necessary for the understanding of detonation front formation and propagation, as well as the fundamental equations of the expansion of detonation products, can be found in the literature. More information about the material modelling and dynamic simulations in Autodyn are also available in [57]. Hereafter, the basic assumptions for material modelling and dynamic simulations are provided together with the model description.

Depending on the case, among other influencing parameters and phenomena, the mechanical model for the materials in use may need to integrate nonlinear response, strain hardening, strain rate, and thermal softening. In general, the modelling of different phenomena can be separated into the equation of state, material strength models, and material failure models. In this specific case, the equation of state (EOS) represents the key aspect for modelling of the propagation of the shock through air.

In general, the EOS for air is commonly given by the ideal gas formulation. The ideal gas equation is derived from the laws of Boyle and Gay-Lussac and requires only the adiabatic exponent $\gamma$ which is given as

$$
p=(\gamma-1) \rho e .
$$




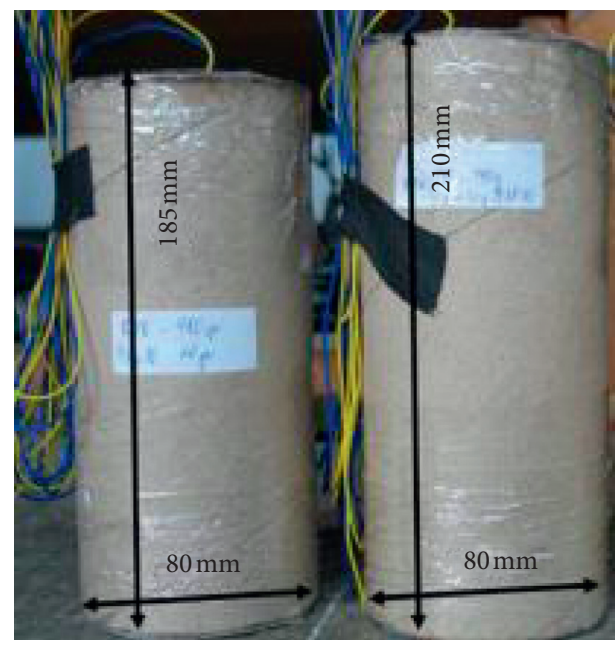

(a)

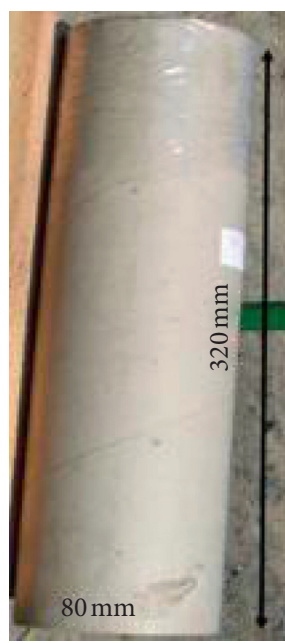

(c)

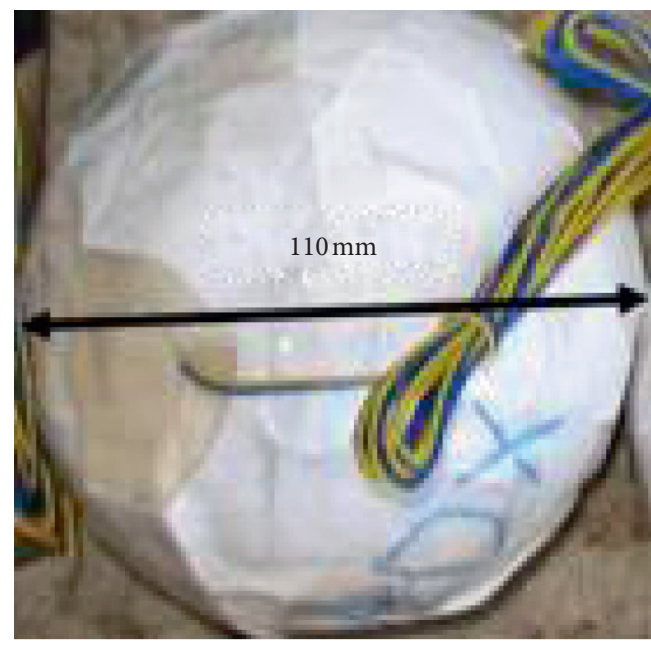

(d)

FIGURE 3: Selection of explosives from the experimental study: (a) RDX cylinder, (b) ANFO, (c) ammonium nitrate, and (d) RDX sphere. In evidence, the size details for the charges.
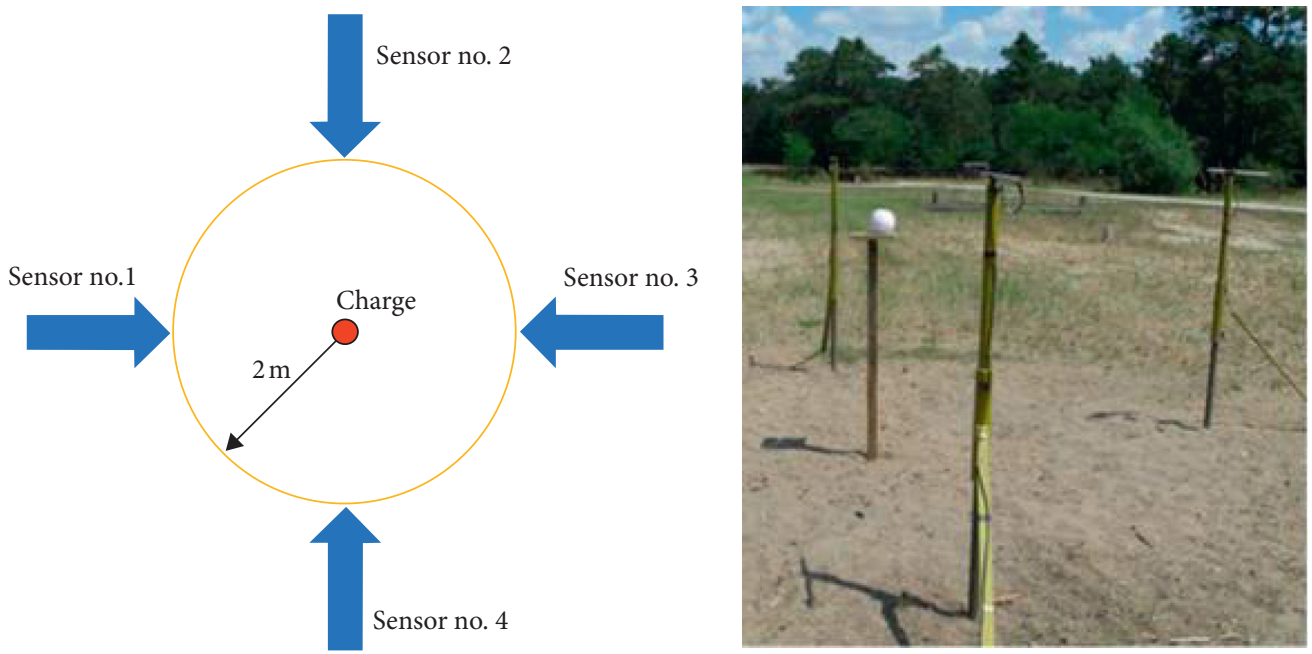

(a)

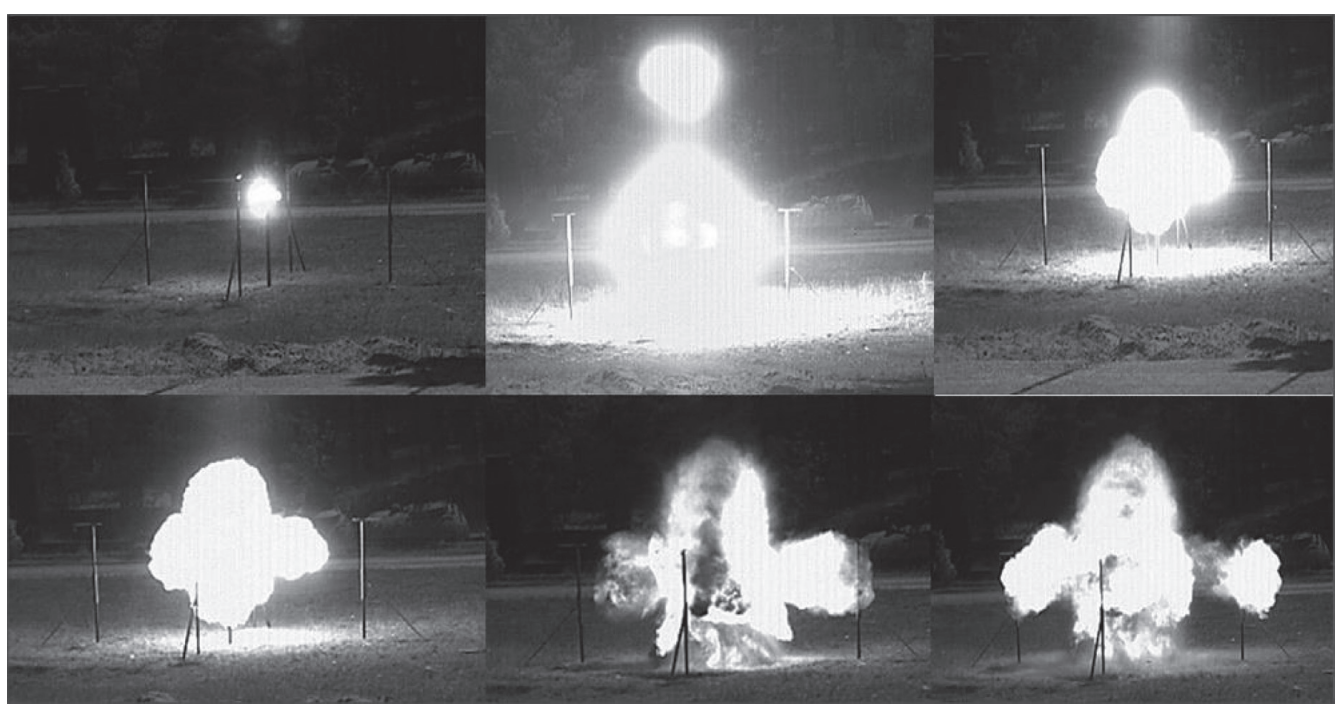

(b)

FIGURE 4: Reference field experiments: (a) setup and (b) sequential propagation of blast waves [54-56]. 
In this research study, air was modelled for the initial pressure of $101.3 \mathrm{kPa}$ by specifying an initial energy of $206.85 \mathrm{GJ} / \mathrm{m}^{3}$. The initial temperature, density, and adiabatic constant $\gamma$ were set to $288 \mathrm{~K}, 1.225 \mathrm{~kg} / \mathrm{m}^{3}$, and 1.4 , respectively.

The relation between state variables of explosive materials is typically given in the form of the Jones-Wilkins-Lee (JWL) EOS and is already defined in the Autodyn material library. The JWL EOS is obtained from the assumed form of the isentropic equation of state combined with the solid Mie-Gruneisen equation of state. The final equation, according to [57], is thus given as

$$
P=A\left(1-\frac{\omega}{R_{1} V}\right) \exp \left(-R_{1} V\right)+B\left(1-\frac{\omega}{R_{2} V}\right) \exp \left(-R_{2} V\right)+\frac{\omega E}{V}
$$

where $A, B, R_{1}, R_{2}$, and $\omega$ are the so-called JWL parameters [57]. At large volumetric ratios, the first two terms of JWL become negligible, and the EOS becomes an ideal gas.

2.3.4. Properties of Selected Explosives. Based on the available experimental feedback, the numerical investigation was focused on the earlier described selection of explosive types, whose charge was modelled as a round (spherical) charge, with the detonation point on its centre. Such an assumption was an implicit limit of the solver that was herein adopted for experimental comparative purposes. To this aim, accordingly, the reference radius of the selected explosives was determined based on the mass and density of each charge, all of which are listed in Table 1.

For the selected explosives, finally, all the input data for the JWL EOS model (and the modified parameters from the Autodyn material library) are listed in Tables 2 and 3.

The explosive detonation point is shown in Figures 5 and 6 and assumed to coincide with the centre of the explosive charge. In the same figures, it is possible to see different material zones and markers (in evidence, the detonation point and the pressure gauges). The main output parameters of the study herein summarized were represented by the pressures recorded at $1 \mathrm{~m}, 2 \mathrm{~m}$, and $3 \mathrm{~m}$ distances from the explosion source. For this reason, gauges \#1, \#2, and \#3 of Figure 5 were defined in the same control points in order to track the corresponding pressure history. In doing so, the reflection of the shock wave from the border of the defined Eulerian domain was prevented by a flow-out boundary condition allowing the material to leave the domain ("flow out"). This boundary condition is represented in Figure 5 by the white line. No additional boundaries were needed to define. In this sense, it is assumed that the explosive charge is set at a height from the ground which allowed the expansion of the blast wave in Figure 4 to be studied in the $1 \mathrm{D}$ domain.

The so-collected numerical results for pressure-time histories were thus compared with selected experimental data of the literature (for the $2 \mathrm{~m}$ distant sensor, in accordance with Figure 4(a)).
TABLE 1: Explosive type and size.

\begin{tabular}{lccc}
\hline Explosive type & Mass $(\mathrm{g})$ & Density $\left(\mathrm{g} / \mathrm{cm}^{3}\right)$ & Radius $(\mathrm{cm})$ \\
\hline RDX & 1700 & 1.83 & 6.05 \\
DAP-2 & 1000 & 0.65 & 7.16 \\
DAP-E & 1000 & 0.65 & 7.16 \\
Polonit-V & 1000 & 0.9 & $6 . .5$ \\
ANFO (homemade) & 1000 & 0.84 & 6.57 \\
\hline
\end{tabular}

2.3.5. Mesh Sensitivity. At the preliminary stage of the numerical study, special care was given to the mesh size of the $1 \mathrm{D}$ elements in use and its related effects (both on the reliability of results and the computational time of analyses). Four different sizes (set in $10 \mathrm{~mm}, 5 \mathrm{~mm}, 1 \mathrm{~mm}$, and $0.5 \mathrm{~mm}$ ) were taken into account, being representative of coarse, medium, fine, and very fine mesh patterns, respectively.

The final mesh size was hence determined by trial and error. From the sensitivity study, more in detail, it was observed that the mesh size of $1 \mathrm{~mm}$ provides satisfactory results, for an acceptable computational time. The influence of the mesh size is demonstrated in Figure 7 for the RDX explosive charge by comparing the pressure history at the distance of $2 \mathrm{~m}$ from the detonation point. The reduction of the element size from $10 \mathrm{~mm}$ to $5 \mathrm{~mm}$ (and then further adapted to $1 \mathrm{~mm}$ ) was found to increase the pressure from $133 \mathrm{kPa}$ to $195 \mathrm{kPa}$ and $316 \mathrm{kPa}$, respectively. The solution already converged for the $1 \mathrm{~mm}$ configuration since the maximum pressure for the element size of $0.5 \mathrm{~mm}$ was predicted in $305 \mathrm{kPa}$.

2.3.6. Analysis of Numerical Results. From the performed numerical simulations, the typical shock wave propagation in air was found to agree with Figure 8, where an example is shown for a selected time instant.

The pressure histories obtained from the simulations in the selected control points (i.e., $1 \mathrm{~m}, 2 \mathrm{~m}$, and $3 \mathrm{~m}$ distances) are also proposed in Figure 9, where the shock wave propagating in the defined domain is shown for different explosive charges. For comparative purposes, the maximum pressure peaks that were collected from gauges \#1, \#2, and \#3 were separately analyzed in the postprocessing stage, see Table 4 .

2.3.7. Experimental and Analytical Comparisons. In order to assess the numerically collected estimates of pressure peaks, some further efforts were carried out with the support of previous analytical outcomes [54-56].

The numerical predictions were first compared with the experimentally measured data of the literature (Table 5). Experimental data, in particular, are proposed in the form of average measurement from the four sensors in Figure 4(a).

As far as Figure 10(a) is taken into account, the experiments were in fact commonly characterized by a scattered distribution of blast waves in the air, hence resulting even in severe variations of pressure peaks, compared to their average value. Such complex real phenomena clearly suggest that the blast wave does not propagate with a regular spherical (or hemispherical) shape (i.e., Figure 1). Once the 
Table 2: Explosive material definition in the numerical model.

\begin{tabular}{lcccc}
\hline Explosive type & Explosive model & Explosive velocity $(\mathrm{m} / \mathrm{s})$ & Heat of combustion $\left(\mathrm{GJ} / \mathrm{m}^{3}\right)$ & Explosive pressure $(\mathrm{GPa})$ \\
\hline RDX & HMX & 8750 & 12.00 & 34.70 \\
DAP-2 & ANFO & 2650 & 2.49 & 2.95 \\
DAP-E & ANFO & 3100 & 2.73 & 4.58 \\
Polonit-V & ANFO & 4000 & 4.62 & 6.93 \\
ANFO (homemade) & ANFO & 1829 & 3.22 & 0.71 \\
\hline
\end{tabular}

TABLE 3: Reference JWL EOS parameters for equation (9).

\begin{tabular}{lcccr}
\hline Explosive type & $\mathrm{A} \times 10^{7}(\mathrm{kPa})$ & $\mathrm{B} \times 10^{6}(\mathrm{kPa})$ & $R_{1}$ & $R_{2}$ \\
\hline RDX & 77.828 & 7.071 & 4.200 & 1.000 \\
DAP-2 & 4.946 & 1.891 & 3.907 & 1.118 \\
DAP-E & 4.946 & 1.891 & 3.907 & 1.118 \\
Polonit-V & 4.946 & 1.891 & 3.907 & 0.300 \\
ANFO (homemade) & 4.946 & 1.891 & 3.907 & 0.333 \\
\hline
\end{tabular}

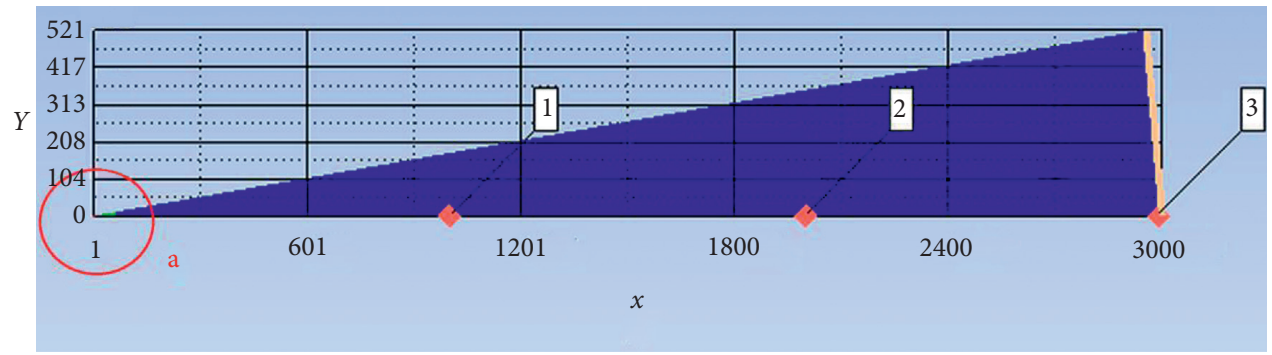

FIGURE 5: 1D wedge element made of the explosive and air zone based on the Euler multimaterial solver (homemade ANFO charge in the example). In evidence, the blast wave pressure at a given distance from detonation point "a." Distance values are given in mm ( $x$-axis), while the pressure values are in $\mathrm{kPa}$.
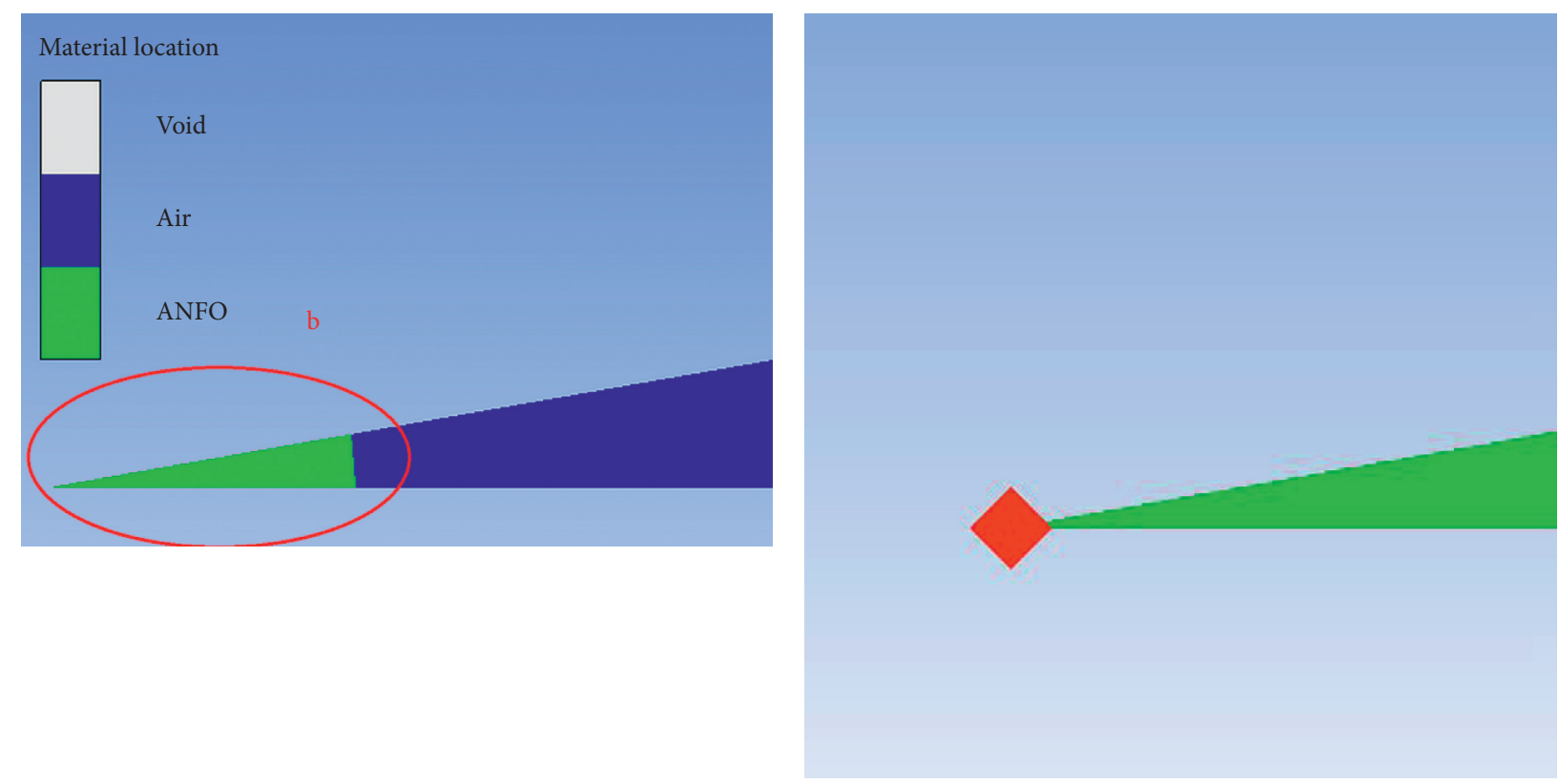

(a)

(b)

Figure 6: Explosive details (homemade ANFO charge in the example): (a) "zone a" (from Figure 5) and (b) detonation point (detail "zone b" from Figure 6(a)). 


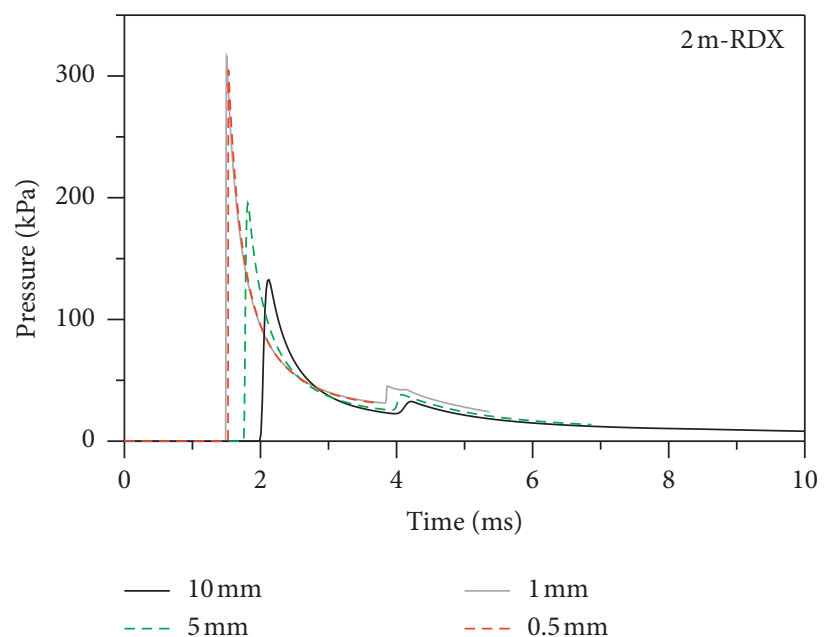

Figure 7: Numerically predicted pressure histories for the RDX explosive, as measured from gauge \#2, as a function of the mesh size.

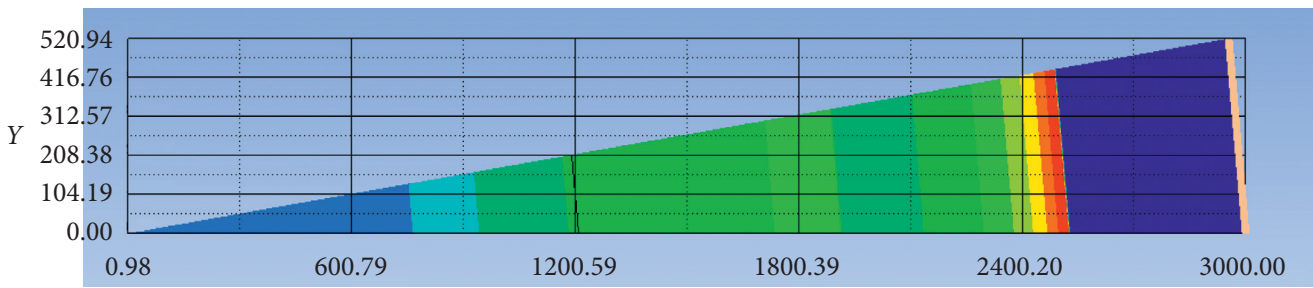

FIGURE 8: Typical numerical result of the shock wave propagating through the air in one direction (homemade ANFO charge in the example). Distance values are given in $\mathrm{mm}$ ( $x$-axis), while the pressure values are in $\mathrm{kPa}$ (example selected at $t=3.16 \mathrm{~ms}$ after the detonation).

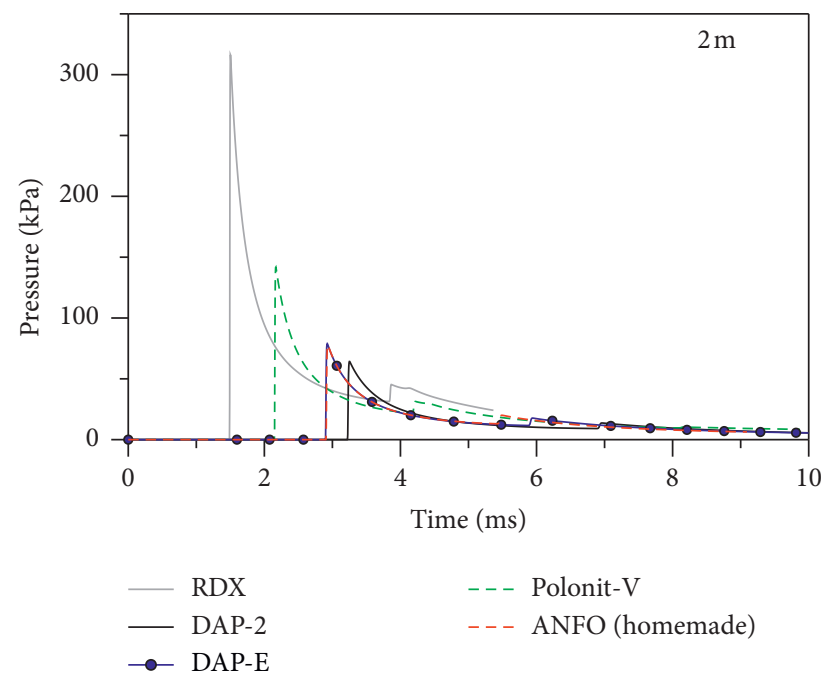

FIGURE 9: Numerically predicted pressure histories for explosives RDX, DAP-2, DAP-E, Polonit-V, and homemade ANFO (propagating through the air in one direction) as measured from gauge $\# 2$.

comparative values in Table 5 are taken into account, where the percentage scatter is proposed for the numerical estimates and the corresponding (average) experimental peaks are proposed, the variability and complexity of blast wave phenomenon estimates are further enforced. The percentage
TABLE 4: Numerically derived pressure peaks at $1 \mathrm{~m}, 2 \mathrm{~m}$, and $3 \mathrm{~m}$ from the detonation point.

\begin{tabular}{lccc}
\hline & \multicolumn{3}{c}{ Pressure $(\mathrm{kPa})$} \\
\hline RDX & $1 \mathrm{~m}$ & $2 \mathrm{~m}$ & $3 \mathrm{~m}$ \\
DAP-2 & 1981.1 & 316.3 & 85.5 \\
DAP-E & 380.0 & 64.2 & 17.2 \\
Polonit-V & 525.0 & 78.9 & 21.1 \\
ANFO (homemade) & 1138.7 & 141.8 & 37.9 \\
\hline
\end{tabular}

scatter of numerical peaks and average experimental peaks is calculated in Table 5 as

$$
\Delta=100 \cdot \frac{X_{\text {num }}-X_{\text {exp }}}{X_{\exp }} .
$$

As far as the explosive charge modifies in Table 5, it is possible to find a rather good agreement with the Polonit- $\mathrm{V}$ estimates $(\Delta \approx+3 \%$ scatter). On the contrary, the ANFO comparisons are strongly overestimated $(\Delta \approx+76 \%)$, and both overconservative and underconservative data can be generally achieved (see the RDX, DAP-2, or DAP-E percentage scatters in Table 5). Worth of interest, in this regard, is also that the overpressure peak is commonly estimated as a primary function of the charge weight (i.e., equations (1) and (3)), but for the given charges (with properties in Table 1), the collected results show a clear lack of uniform correlation 
TABLe 5: Numerically and experimentally derived pressure peaks at $2 \mathrm{~m}$ from the detonation point.

\begin{tabular}{lccc}
\hline & \multicolumn{2}{c}{$\begin{array}{c}\Delta(\%) \\
\text { Equation (10) }\end{array}$} \\
\hline RDX & Numerical & Exsure $(\mathrm{kPa})$ & 17.63 \\
DAP-2 & 316.3 & 268.9 & -20.64 \\
DAP-E & 64.2 & 80.9 & -31.51 \\
Polonit-V & 78.9 & 115.2 & 3.13 \\
ANFO (homemade) & 141.8 & 137.5 & 76.02 \\
\hline
\end{tabular}

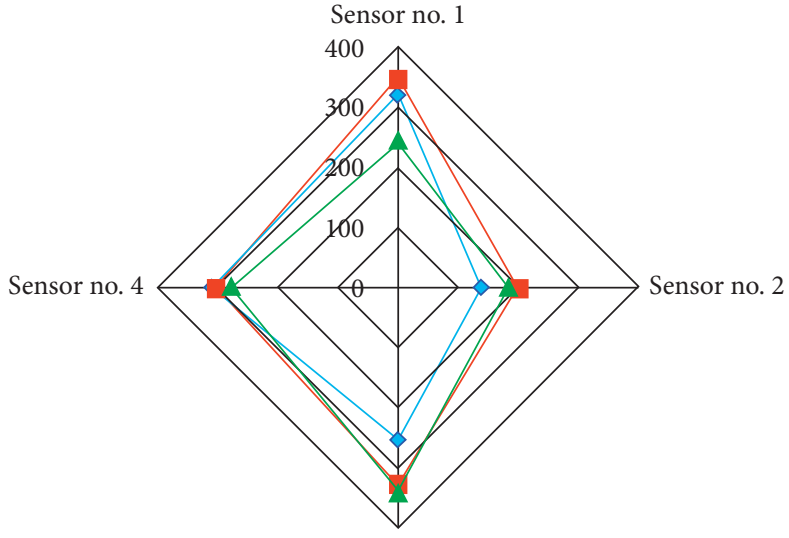

Sensor no. 3

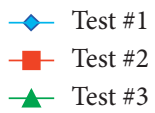

(a)

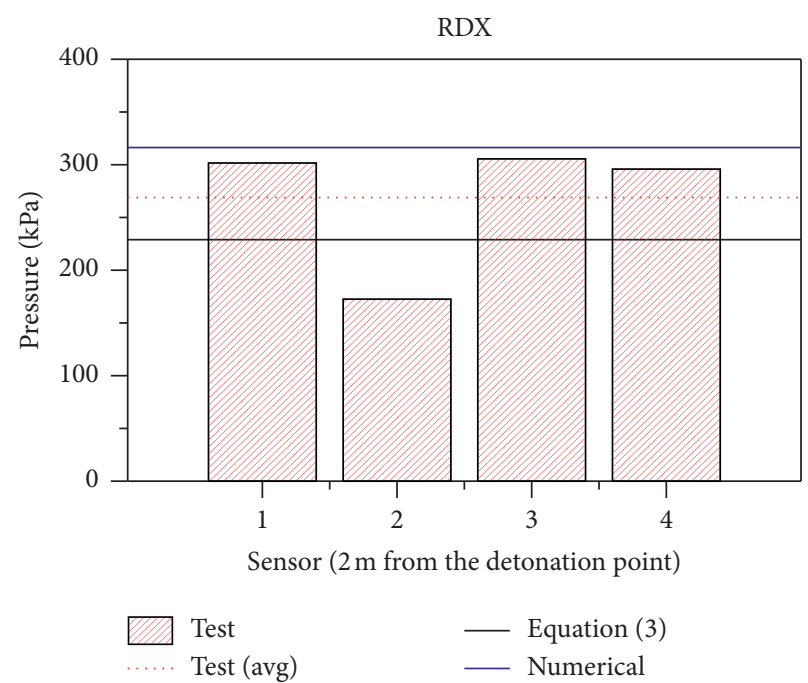

(b)

FIGURE 10: Experimental, analytical, and numerical pressure peaks: (a) example of a typical experimental record (RDX charge, pressure values in $\mathrm{kPa}$, and at $2 \mathrm{~m}$ from the detonation point) and (b) the corresponding pressure peak comparisons (RDX).

with $W$ (or $W_{\mathrm{R}}$ ). The uncertain prediction of the expected overpressure peaks due to a given charge, accordingly, can have severe effects of the final choices of design for blastresisting structures and facilities.

As far as the peak estimate is assessed in the form of the modified analytical equation recalled in equation (3), typical comparisons agreeing with Figure 10(b) can be obtained. There, the experimental measurements are proposed in the form of independent peaks recorded at the four gauges with their average value, as well as in the form of pressure peaks given by equation (3) and by the Autodyn numerical model, respectively.

\section{Conclusions}

Explosions, as known, represent extreme and rather complex phenomena that should be properly taken into account in the design of engineering facilities. Design tools for blastresisting or blast-retrofitted structures can offer a strong support to ensure appropriate safety levels. However, multiple aspects can strongly affect the evolution and amplitude of blast events and all the related phenomena (including the shape, size, and type of the explosive charge). In this regard, the blast wave propagation in air was explored in this paper with the support of the ANSYS Autodyn solver.
Major advantage was derived from experimental overpressure peaks that were recorded from a series of field experiments on RDX, DAP-2, DAP-E, Polonit-V, and homemade ANFO charges.

From the numerical investigation herein reported, as also in agreement with previous literature studies, it was in particular observations that

(i) From a theoretical point of view, a given blast wave is theoretically assumed to propagate in the form of a sphere or hemisphere, with symmetrical and regular shape. However, according to the selected experiments, field measurements confirm the complexity and the irregular trend of real phenomena.

(ii) Several theoretical models and recommendations of the literature are made for the ideal spherical explosive charge. In the reality (and mainly in the cases of terrorist attacks, where homemade charges are commonly used), the shape, size, and type of charge (i.e., explosive belt, vest, suitcase, etc.) can thus strongly differ from the reference assumptions and thus result in even more severe events;

(iii) Both analytical and more advanced numerical models can offer a strong support to designers. As 
far as the charge features can modify, however, the corresponding overpressure peak estimates are strongly sensitive to input parameters and could result both in over- or underconservative predictions, with severe effects on the design assumptions for blast-resisting and blast-protective structures.

\section{Data Availability}

The data used to support the findings of this study are available from the corresponding author upon request.

\section{Conflicts of Interest}

The authors declare that there are no conflicts of interest regarding the publication of this paper.

\section{References}

[1] F. Hamdan, "Structural Strengthening of Offshore Topsides Structure as Part of Explosion Risk Reduction Methods," Steel Construction Institute, Ascot, UK, 2006.

[2] T. Ngo, P. Mendis, A. Gupta, and J. Ramsay, "Blast Loading and Blast Effects on Structures-an Overview," The University of Melbourne, Melbourne, Australia, 2007.

[3] P. A. Buchan and J. F. Chen, "Blast resistance of FRP composites and polymer strengthened concrete and masonry structures-a state-of-the-art review," Composites Part B: Engineering, vol. 38, no. 5-6, pp. 509-522, 2007.

[4] D. Čekerevac, C. Rigueiro, and E. Pereira, "Characterization of accidental scenarios for offshore structures," Ce/Papers, vol. 1, no. 2-3, pp. 4341-4350, 2017.

[5] V. Karlos, M. Larcher, and G. Solomos, "JRC Science for Policy Report: Review on Soft target/Public Space Protection Guidance," Publication office of the European Union, Luxembourg, Luxembourg, 2018.

[6] B. T. Bennett, Understanding, Assessing and Responding to Terrorism: Protecting Critical Infrastructure and Personnel, John Wiley \& Sons, Hoboken, NJ, USA, 2nd edition, 2018.

[7] D. B. Hayes, Introduction to Stress Wave Phenomena, Sandia Laboratories, Albuquerque, NM, USA, 1976.

[8] Z.-Y. Liu, "Overdriven Detonation Phenomenon and its Applications to Ultra-high Pressure Generation," Kumamoto University, Kumamoto, Japan, 2001.

[9] Autodyn Simulation, in 12th Congress of Steel and Composite Structures, Coimbra, Portugal, 2019.

[10] E. L. Lee, H. C. Hornig, and J. W. Kury, "Adiabatic Expansion of High Explosive Detonation Products," Lawrence Radiation Laboratory University of California, Livermore, CA, USA, 1968.

[11] H. Hamashima, Y. Kato, Y. Nadamitsu, and S. Itoh, "Determination of JWL parameters from underwater explosion test for ideal and non-ideal explosives," Science and Technology of Energetic Materials, vol. 64, no. 6, pp. 248-253, 2003.

[12] Z. Xue and J. W. Hutchinson, "A comparative study of impulse-resistant metal sandwich plates," International Journal of Impact Engineering, vol. 30, no. 10, pp. 1283-1305, 2004.

[13] J. W. Hutchinson and Z. Xue, "Metal sandwich plates optimized for pressure impulses," International Journal of Mechanical Sciences, vol. 47, 2005.

[14] A. Vaziri and J. W. Hutchinson, "Metal sandwich plates subject to intense air shocks," International Journal of Solids and Structures, vol. 44, no. 6, pp. 2021-2035, 2007.
[15] Z. Xue and J. W. Hutchinson, "Preliminary assessment of sandwich plates subject to blast loads," International Journal of Mechanical Sciences, vol. 45, no. 4, pp. 687-705, 2003.

[16] V. Rubino, V. S. Deshpande, and N. A. Fleck, "The dynamic response of end-clamped sandwich beams with a Y-frame or corrugated core," International Journal of Impact Engineering, vol. 35, no. 8, pp. 829-844, 2008.

[17] R. Alberdi, J. Przywara, and K. Khandelwal, "Performance evaluation of sandwich panel systems for blast mitigation," Engineering Structures, vol. 56, 2013.

[18] S. C. K. Yuen, G. Cunliffe, and M. C. du Plessis, "Blast response of cladding sandwich panels with tubular cores," International Journal of Impact Engineering, vol. 110, pp. 266-278, 2017.

[19] F. Zhua, L. Zhaoa, G. Lua, and Z. Wang, "Deformation and failure of blast-loaded metallic sandwich panels-experimental investigations," International Journal of Impact Engineering, vol. 35, 2008.

[20] X. Li, W. Z. Zhang, G. Wu, and L. Zhao, "Dynamic behaviour of aluminium honeycomb sandwich panels under air blast: experiment and numerical analysis," Composite Structures, vol. 108, pp. 1001-1008, 2014.

[21] X. Li, Z. Wang, F. Zhu, G. Wu, and L. Zhao, "Response of aluminium corrugated sandwich panels under air blast loadings: experiment and numerical simulation," International Journal of Impact Engineering, vol. 65, 2014.

[22] H. S. Eide and E. A. Melby, "Blast Loaded Aluminium Plates," Norwegian University of Science and Technology, Trondheim, Norway, 2013.

[23] T. A. Hustad and A. L. Lindland, "Aluminum Structures Exposed to Blast Loading," Norwegian University of Science and Technology, Trondheim, Norway, 2014.

[24] T. Børvik, A. Hanssen, S. Dey, H. Langberg, and M. Langseth, "On the ballistic and blast load response of a $20 \mathrm{ft}$ ISO container protected with aluminium panels filled with a local mass-phase I: design of protective system," Engineering Structures, vol. 30, no. 6, pp. 1605-1620, 2008.

[25] T. Børvik, A. Burbach, H. Langberg, and M. Langseth, "On the ballistic and blast load response of a $20 \mathrm{ft}$ ISO container protected with aluminium panels filled with a local massphase II: validation of protective system," Engineering Structures, vol. 30, no. 6, pp. 1621-1631, 2008.

[26] L. Figuli, C. Bedon, Z. Zvaková, Š. Jangl, and V. Kavický, "Dynamic analysis of a blast loaded steel structure," Procedia Engineering, vol. 199, pp. 2463-2469, 2017.

[27] A. A. Nassr, A. G. Razaqpur, M. J. Tait, M. Campidelli, and S. Foo, "Strength and stability of steel beam columns under blast load," International Journal of Impact Engineering, vol. 55, pp. 34-48, 2013.

[28] K. Lee, T. Kim, and J. Kim, "Local response of W-shaped steel columns under blast loading," Structural Engineering and Mechanics, vol. 31, no. 1, pp. 25-38, 2009.

[29] M. Momeni, M. A. Hadianfard, C. Bedon, and A. Baghlani, "Damage evaluation of $\mathrm{H}$-section steel columns under impulsive blast loads via gene expression programming," Engineering Structures, vol. 219, Article ID 110909, 2020.

[30] J. Štoller and E. Zezulová, “The application of fibre reinforced concrete for protective shelter from auxiliary material," Key Engineering Materials, vol. 755, pp. 374-381, 2017.

[31] J. Stoller and E. Zezulová, "Field tests of cementitious materials suitable for force protection and critical infrastructure protection," in Proceedings of the 2019 International Conference on Military Technologies (ICMT), Brno, Czech Republic, May 2019. 
[32] R. Hajek and M. Foglar, "The reduction of peak overpressure using concrete blast barriers," Structures Under Shock and Impact XIII, pp. 1-8, 2014.

[33] A. Remennikov, T. Ngo, D. Mohotti, B. Uy, and M. Netherton, "Experimental investigation and simplified modeling of response of steel plates subjected to close-in blast loading from spherical liquid explosive charges," International Journal of Impact Engineering, vol. 101, pp. 78-89, 2017.

[34] S. N. Raman, T. Ngo, P. Mendis, and T. Pham, "Elastomeric polymers for retrofitting of reinforced concrete structures against the explosive effects of blast," Advances in Materials Science and Engineering, vol. 2012, Article ID 754142, 8 pages, 2012.

[35] C. E. Greene and J. J. Myers, "Flexural and shear behavior of reinforced concrete members strengthened with a discrete fiber-reinforced polyurea system," Journal of Composites for Construction, vol. 17, no. 11, 2013.

[36] S. M. R. Khalili, M. Najafi, and R. Eslami-Farsani, "Effect of thermal cycling on the tensile behavior of polymer composites reinforced by basalt and carbon fibers," Mechanics of Composite Materials, vol. 52, no. 6, pp. 807-816, 2017.

[37] E. B. Pereira, G. Fischer, and J. A. O. Barros, "Effect of hybrid fiber reinforcement on the cracking process in fiber reinforced cementitious composites," Cement and Concrete Composites, vol. 34, no. 10, pp. 1114-1123, 2012.

[38] E. B. Pereira, G. Fischer, and J. A. O. Barros, "Direct assessment of tensile stress-crack opening behavior of Strain Hardening Cementitious Composites (SHCC)," Cement and Concrete Research, vol. 42, no. 6, pp. 834-846, 2012.

[39] L. Correia, J. Sena-Cruz, J. Michels, P. França, E. Pereira, and G. Escusa, "Durability of RC slabs strengthened with prestressed CFRP laminate strips under different environmental and loading conditions," Composites Part B: Engineering, vol. 125, pp. 71-88, 2017.

[40] X. Zhang and H. Hao, "The response of glass window systems to blast loadings: an overview," International Journal of Protective Structures, vol. 7, no. 1, pp. 123-154, 2016.

[41] M. Larcher, M. Arrigoni, C. Bedon et al., "Design of blastloaded glazing windows and façades: a review of essential requirements towards standardization," Advances in Civil Engineering, vol. 2016, Article ID 2604232, 14 pages, 2016.

[42] H. D. Hidallana-Gamage, D. P. Thambiratnam, and N. J. Perera, "Design guidance for blast-resistant glazing," Journal of Architectural Engineering, vol. 21, no. 3, Article ID 4015003, 2015.

[43] J. Pelfrene, J. Kuntsche, S. Van Dam, W. Van Paepegem, and J. Schneider, "Critical assessment of the post-breakage performance of blast loaded laminated glazing: experiments and simulations," International Journal of Impact Engineering, vol. 88, pp. 61-71, 2016.

[44] M. Larcher, F. Casadei, and G. Solomos, "Simulation of blast waves by using mapping technology in EUROPLEXUS," JRC Technical Report JRC91102, Publications Office of the European Union, Luxembourg, Luxembourg, 2014.

[45] X.-W. Hong, W.-B. Li, W. Cheng, W.-B. Li, and H.-Y. Xu, "Numerical simulation of the blast wave of a multilayer composite charge," Defence Technology, vol. 16, no. 1, pp. 96-106, 2020.

[46] B. Vanderstraeten, M. Lefebvre, and J. Berghmans, "A simple blast wave model for bursting spheres based on numerical simulation," Journal of Hazardous Materials, vol. 46, no. 2-3, pp. 145-157, 1996.
[47] Y. Shi, H. Hao, and Z.-X. Li, "Numerical simulation of blast wave interaction with structure columns," Shock Waves, vol. 17, no. 1-2, pp. 113-133, 2007.

[48] W. Z. Xu, X. S. Kong, C. Zheng, and W. G. Wu, "Numerical method for predicting the blast wave in partially confined chamber," Mathematical Problems in Engineering, vol. 2018, Article ID 2530239, 17 pages, 2018.

[49] H. L. Brode, "Numerical solution of spherical blast waves," Journal of Applied Physics, American Institute of Physics, Ney York, NY, USA, 1955.

[50] C. A. Mills, "The design of concrete structure to resist explosions and weapon effects," in Proceedings of the 1st International Conference on Concrete for Hazard Protections, pp. 61-73, Edinburgh, UK, 1987.

[51] N. M. Newmark and R. J. Hansen, Harris, "Design of blast resistant structures," in Shock and Vibration Handbook McGraw-Hill, New York, NY, USA, 1961.

[52] H. Draganic and V. Sigmund, "Blast loading on structures," Tehnički Vjesnik, vol. 19, no. 3, pp. 643-652, 2012.

[53] J. Henrych, "The Dynamics of Explosion and its Use," Elsevier Scientific Publishing Company, Amsterdam, Netherlands, 1979.

[54] L. Figuli, V. Kavický, Z. Ligasová, and P. Maňas, "Influence of homemade ammonium nitrate and fuel oil explosives charge shapes on blast wave propagation," International Journal of Computational Methods and Experimental Measurements, vol. 4, no. 3, pp. 213-220, 2016.

[55] L. Figuli, V. Kavický, Š. Jangl, and Z. Zvaková, "Comparison of the efficacy of homemade and industrially made Anfo explosives as an improvised explosive device charge," Communications: Scientific Letters of the University of Žilina, vol. 20, no. 2, pp. 23-27, 2018.

[56] V. Kavicky, L. Figuli, S. Jangl, and Z. Ligasová, "Influence of homemade ammonium nitrate and fuel oil explosives charge shapes on blast wave propagation," WIT Transactions on the Built Environment, vol. 141, pp. 297-309, 2014.

[57] ANSYS, ANSYS Autodyn User's Manual, ANSYS, Inc., Canonsburg, PA, USA, 2013. 